\title{
Online Learning Before, During and After COVID-19: Observations Over 20 Years
}

\author{
https://doi.org/10.3991/ijac.v13i2.16779 \\ Natalie Wieland \\ VidVersity/Co-Founder, Melbourne, Australia \\ natalie@vidversity.com \\ Liz Kollias \\ VidVersity/Client and Communications Manager, Sydney, Australia
}

\begin{abstract}
Natalie Wieland has been delivering online learning for over 15 years as both a lecturer and workplace trainer. In this paper, she reflects on how digital learning has evolved from the days of moving PowerPoints to the highly polished and produced modules with an equally high price. She also reviews the first response during COVID-19 when so many rushed to deliver their content online, using tools such as Zoom, and provides some thoughts on what we have learned during this period, including the need to provide synchronous and asynchronous learning, the need to include the educator in the process and empower them with digital tools to create online content and the need to make online learning authentic and not over produced. It still is content and design that is critical. Wieland offers some predictions around what the future will look like with digital learning in the workplace, with the lessons we have all learned.
\end{abstract}

Keywords - digital workplace learning, digital learning first response during COVID-19, empowering educators, digital learning post COVID-19

\section{$1 \quad$ Introduction}

I studied law and then IT in the early 1990s. This combination of disciplines was unique at that time and led me to my first role outside a traditional law firm with the legal publisher Lexis Nexis. My role included teaching judges in Victoria, Australia on how to use CD-ROMs for legal research. The challenge of enabling these traditionally trained and largely conservative and reluctant learners to access new technology ignited a spark in me and I have been in the ed tech space ever since as a teacher, a consultant and as a tech entrepreneur creating online platforms for the creation and delivery of video content.

In some ways, those early lessons in making technology accessible to everyone and using teaching skills to bridge the knowledge gap for my students have never left me and continue to drive my approach to innovation and teaching today.

I have been incredibly fortunate that my own career trajectory has aligned with the evolution of the various technologies we take for granted today. Mobile technology, 
interactivity, accessible content creation platforms and what I call the 'democratization' of the online space have all evolved to bring more and more tools to me as a teacher and as an entrepreneur in the world of online learning.

From my unique perspective as a former lawyer and my current roles as a teacher and tech entrepreneur, I would like to share my insights into the evolution of online learning and on how I see the future for learners and for Learning and Development professionals. Whist I had already begun work on this paper prior to the current pandemic crisis, humanity has been catapulted into the online space whether we like it or not. We may not feel comfortable to find ourselves suddenly online all the time, but how grateful we are now that the technology exists. In the 1990s those judges I was introducing to new technologies felt just as uncomfortable and resigned to the shift in the world. The challenge now for us as teachers and innovators is to ensure an easy transition for everyone seeking to access the available technologies to continue to do their job effectively. The pandemic creates a marker in history. So, let's look at the world before the pandemic, how the current crisis impacts us from the perspective of online learning and what the future looks like for learners, teachers and providers.

\section{Before COVID-19: Face-to-Face Versus Online Learning}

To be frank, online learning has a bad reputation, perceived by many as the 'poor cousin' of face-to-face training. So how has this reputation come about and is it warranted?

Early versions of online delivery were hampered by the tools available to content creators. Interactions were limited or clunky. The first of the cloud-based solutions grappled with the challenges of delivery on multiple browsers and various browser versions. This created frustrations for learners in terms of load time, buffering and other 'clunky' functionality. Whilst the mode of delivery and framework was basic and imperfect, the ability to create and deliver online training was revolutionary in terms of accessibility for learners and in providing a cost effective and scalable solution for employers and trainers.

Even in the past few years, innovations have continued at an incredible rate. There is now a plethora of authoring tools and online platforms including live streaming platforms and discussion rooms. Just as teachers use a range of teaching tools and methodologies in a live classroom setting, there is a smorgasbord of online options. Notwithstanding, I continue to see headlines such as "Online learning is not as effective as classroom training" so the 'bad reputation' has continued to plague the world of online learning.

In the transition to online learning, it is important not to become distracted by modes of learning delivery and what we may perceive as limitations. I believe strongly that the content being delivered, and the individual teaching style of the teacher or subject matter expert should remain paramount. Let me give you an example of what I mean. My children are currently learning from home. Without exception, the best teachers are still doing great teaching even though they are no longer in the classroom and the average teachers are still delivering average teaching 
experiences online. The mode has changed nothing. A talented and enthusiastic science teacher created kits for the kids which were collected by the parents just before the lockdown. During Zoom lessons, the teacher creates breakout rooms for the kids, remains available throughout the lesson, and creates a 'quirky' experience during each lesson, a pet break for example. The teaching style is unchanged in so far as the teacher is providing the kids with tools to learn, a 'lecture style' component, followed by group work and a 'surprise' element to ensure engagement. These elements are present in both the live classroom and the online delivery. The kids are engaged and motivated and the mode of delivery has not impacted the quality of their learning.

Teaching is an art and a skill, and in any format, there are great experiences and forgettable experiences. I recently did some research around what makes a great teacher and the key terms that kept coming up, whether I interviewed a 12-year-old, a 22-year-old in college or a 45-year-old at work, were 'passion' and 'confidence'. Those traits are not unique to face-to-face teaching but rather they are unique to great teachers. So, the key is translating that into the online space. I cannot put it any better than Stephen Downes who wrote, "Online learning should be fast, fun, crazy, unplanned and inspirational. It should be provided by people who are more like DJs than television producers. It should move and swim, be ad hoc and on the fly. I wish educators could get out of their classroom mindsets and actually go out and look at how the rest of the world is doing online learning. Watch a dance craze spread through TikTok, follow through-hikers on YouTube, organize a community in a Facebook group, discuss economic policy in Slack. All of that is online learning - and resolutely not the carefully planned courses that are over-engineered, over-produced, over-priced and over-wrought".

So how and why do we still have this divide between 'online' and 'face-to-face'? I have spent a lot of time pondering this and I make the following observations.

\subsection{This disconnection between the teacher and the learner}

Until very recently, online content required an instructional designer and a coder or tech builder. The teacher had of course already created and 'designed' the content however the introduction of the technical or design 'middle person' enabled that content to be packaged to fit into online frameworks. Over time, this process alienated the teachers or SMEs (subject matter experts) from the delivery and often stripped away the personal teaching style. The degree of technical and design skill involved also made online content creation difficult, technically challenging and timeconsuming. This alienation of the teacher or SME from the 'end product' has now become an obstacle for teachers in providing an agile solution and to deliver content fast and effectively. I believe this has also cemented the reputation of online learning as being inaccessible and impractical.

Many teachers perceive online modes as difficult or beyond their scope or ability and will avoid the process altogether. Others engaged in the process with instructional designers will be dissatisfied with the outcome which becomes sanitized or devoid of the characteristics and unique style of the teacher. More importantly, this sense of 
disconnection was also experienced by students who lost the original 'flavor' of that teacher's individual style and approach and the outcome became a kind of one-sizefits-all formulaic delivery of content.

The key to elevating the reputation of online and the real experience of those creating it and those consuming it is in breaking down this stepped process and giving the power of creativity back to the teacher. Digital 'natives' (kids born after 1985) with no experience of a world without technology are not hampered by this dichotomous approach to 'live' versus online learning. Look no further than the incredible success of YouTubers teaching gaming techniques, craft, makeup, styling, music. They are all teaching, they are all connecting with their audience, and they are doing so with a rawness and authenticity without compromising 'learning outcomes' which incidentally are being met! We need to embrace this spontaneous approach to online learning across all sectors and I believe instructional designers have a big part to play in this cultural shift.

\subsection{Educators lost control of the content}

In many ways, the technology has controlled the content and relegated individual teaching styles and creative approaches to teaching to second place.

Authoring tools such as Articulate, Rise, Captivate and the like have provided a framework for content creation and have been incredibly important in creating accessibility. But the predetermined frameworks which are the necessary basis of these platforms also work against individualism and creativity. The process for creation is still challenging, often requires an 'expert' to do the course design and building and so are often only suited to reasonably static content. Very few educators will be able to get up in the morning and create a course for students by lunchtime using these platforms. They have a place and an application, but they are not the answer for most.

Happily, innovative designs and a smorgasbord of tools have emerged to put content control back into the hands of teachers. However, they also need to operate within the rules and frameworks of the institutions in which they operate. It is imperative that universities, schools, colleges and workplaces ensure educators are given access and training in use of these tools, that these work within existing Learning Management Systems. Most importantly, there must be a culture of innovation and risk taking in the move to online delivery. Unless we encourage our educators to try new technologies, experiment and develop new skills, we continue to be at risk of alienating learners and simply being left behind.

\section{During COVID-19}

COVID-19 has pushed everyone online overnight and it's unlikely that the old modes of work will resume in the short term, if at all. From a teaching perspective, the impact has been the greatest on those that were least prepared and were still residing entirely in the old mode of face-to-face delivery. It is akin to an army being 
trained in hand-to-hand to combat when the enemy is trained in cyberattacks. We all looked to our educators and said, "come on you need to keep our staff trained, our kids educated and do it fast".

Understandably, many have brought the old dichotomy of 'live' and 'online' with them and have sought to rely entirely on Zoom or similar platforms in an attempt to do what they did before in a live online environment. Try a Zoom call for 45 minutes with a group of 30 7-year-olds or induction training for 25 graduates. The result is noise, distraction, lack of engagement and incredibly stressed teachers. It is a tremendous challenge for which we have failed to equip our educators and experts.

As part of my role as a consultant, I started working with academics and other consultants in mid-March 2020 to help them to meet these new challenges and to access the various digital offerings. What I found was shocking. To provide you with some perspective, I have been working at tertiary level for many years and I bet my career on the need to provide genuinely accessible tools for educators and SMEs to create their own digital content. In 2017 I co-founded a company called VidVersity to meet this need by creating a video-based content creation platform. So I was aware that there was an issue with technology and educators. What I didn't realize was how dramatically this would become an issue with a direct impact on the mental health and well-being of teachers and students.

I found highly educated people in a tailspin, in tears, with little knowledge of what was required to move online. I am currently working with professors, consultants and trainers from the UK, Switzerland, Australia, New Zealand and more, and the theme was universal; they didn't know where to start. My passion has been to put online tools in the hands of the experts, and it upsets me that as an industry we had failed to properly equip our 'army' of educators. We had taken the tools of the trade off them and created a secret process whereby they provide the content and then they are promptly sidelined. Suddenly they are back in the frontline with little or no training.

One of the greatest outcomes of this horrendous period is what many simply call the "first response". The first response has created an environment where we have a true "growth mindset". No proposition is too crazy, no one is criticized for failing and we are all learning at an incredible rate as to what is possible. The outcome is often challenging, raw, inspiring and every day we are discovering new and surprising ways of doing things.

\section{$4 \quad$ Beyond the First Response}

So, where do we go from here? I see the solution in two stages. As we settle into the 'new normal' of the pandemic, we will see a refinement in the way we curate and deliver our teaching content and engage with learners. Later, as we resume face-toface training, I believe there will be a dramatic shift in setting up safeguards to ensure 'online only' mode can be resumed at any time but that we can also retain the best of what we have discovered in these times of difficulty.

As many have predicted, video has been a key part of this first response, and I believe it is here to stay. 
Unless you have lived under a rock, you will know that YouTube is a go-to for thousands for education, whether that be how to sew a scarf, play drums or learn a language. In effect it has been a learner-driven revolution. So, whilst many of us have been evaluating the benefits of video in education, the learners just jumped in and embraced it.

The benefits are self-evident. It is readily accessible to view and to create. Cloud storage has created ease of moving video and internet speeds have created a stable point of access.

Is video the silver bullet? Of course not. But this is a big piece of the puzzle. We need to help educators get comfortable with accessing video, helping them speak confidently to their smartphone, to bring their creativity to the table with an eye to what their own phone can capture.

Most importantly, we need to browse the options. Just as we no longer lecture students without engagement, we need to curate learning experiences from the various modes of delivery available to them.

A very senior consultant who provides leadership training around the globe rang me to say he had never delivered online, he had 24 workshops booked for the rest of the year and without them he would have no income and he had no idea where to start. I sat with him (on Zoom) and we broke down his content. Rather than get distracted by how he would do this, we started by looking at what a great day would look like to him. We then looked at the content he had which is typical of most teachers, namely:

a) The material he presents to them, i.e., static content

b) The activities he gives them

c) Discussions

We then assessed which technology would best suit each of these parts.

a) For the static content he needed a way to easily film, edit and cut the content into shorter sections. We did this by using Loom to record his screen, his phone to record himself and a platform to edit and curate (VidVersity).

b) He then created activities using HP5 and PowerPoint.

c) For discussions, we scheduled live Zoom calls and scheduled times to enable students to first complete the pre-recorded content and the activities.

So, what does this demonstrate? Firstly, start with how a teacher likes to teach. This is likely to be his or her strength so let's not take it away. Then next look at the simplest way to transition this to an online environment by breaking it down into methods of delivery and then matching this to the technology available. Lecture style delivery to a room of students can be matched by simply recording that same content with the same pizzazz and panache (or lack!) that the teacher usually employs.

The teacher remained in control of his content and then only needed to become comfortable with the technology. This might sound overwhelming but in five training sessions of 1 hour each, this teacher had delivered four workshops online and was creating a whole suite of material ready for our brave new world. He had retained 
those traits that my survey had identified as the most important for students, passion and confidence.

Here is another example: a lecturer had been told to record his content to PowerPoint. He said to me "I don't have any PowerPoints" (he had never used them). I asked how he would normally present his content and he said, "I teach engineering, so I walk around my city and take them on a tour". So, this is exactly what he did. He took his phone and filmed a tour of his city. He was able to do so without breaking lockdown rules (this is work and he was alone) without any complex technology or change to his content.

The video was uploaded to Dropbox and a link sent to his students.

That night he rang me to say how much his students had loved it and how all his apprehension had dissolved. Now his imagination is sparked, and he is off and running.

And for one final example, this time from the corporate world. Last year I was working with a large multinational engineering company. They had too many injuries at work. My brief was to review the health and safety training. The company had invested in an online offering that was slick and highly produced. It was however confusing and unrelatable for the intended audience of workers. I went to one of the construction sites and spoke to a foreman about the safety issues. His chief concern was that no worker that came to the site was properly briefed or prepared and the safety training was ineffective. I took out my phone to film, sat in his shed and asked, "what are the top 10 things you need to know to be safe on the site?" The foreman spoke without hesitation and in the natural and charismatic way that he would normally speak to his team. Using that content, I then created a short video with links to all the policies and some basic quizzes and made it available to the employees. Within six months injury statistics were positively impacted and importantly, this content could be easily updated to respond to new challenges.

\section{Why was this more effective?}

1. It was authentic. This was not an actor but a real foreman from a real site. This immediately created a sense of trust for the audience.

2. It was delivered in a way that was digestible to the audience. The previous training had loads of beautiful pages outlining learning objectives. The construction workers accessing this couldn't care less. Know your audience.

3. The foreman who was the SME believed in the process and promoted it. This created authenticity in delivery.

4. The technology was so easy to use that the company empowered the SMEs to build content for training. That sense of ownership leads to current and relevant content constantly being made available to staff when it was needed. Content was created immediately to respond to address and reduce genuine risk.

\section{The Future for Learning and Development Professionals}

The role of the modern L\&D professional is always evolving, and learning is what we do best. My hope is we don't simply go back to old habits once the world opens again but embrace the opportunities for change and innovation that this dramatic 
event has afforded us. These are the opportunities I see for all of us as Learning and Development professionals.

\subsection{Redefine online learning}

We need to redefine online learning and look beyond the idea of SCORM-based highly structured content to embrace the vast array of digital experiences on offer. These range from TikTok to MOOCs. If we begin with the conviction that experienced educators know how to design content using sound education principles, our role is to give them access to all the tools and training they need to curate a great experience for their students. They need choices and they need skills in new technologies.

\subsection{Provide a seat at the table for educators}

It is so important to invite educators back into the process. After working with teachers, trainers and lecturers over the last few weeks, my biggest lesson is to remember they are the authors of the content and understand it better than anyone. Our job as instructional designers, digital transformation coaches and L\&D advisers, is to guide them over the bridge to digital delivery rather than to be prescriptive. When a teacher tells me he or she is stressed saying they cannot reduce their content to a 15-minute video as they have been advised to do, my reply is simply, "well, don't! There are other ways and I can show you what is possible". Digital delivery does not mean the content needs to be compromised or 'watered down'. Design is crucial but that does not mean you have to follow a digital recipe. Don't underestimate how much design work SMEs do for classes, workshops, lectures, etc. Let's help them deliver differently.

\subsection{We listen to the learner}

Teachers and educators are always focused on their students. This should also be a key focus for designers and L\&D professionals. What do our learners want? What should we be doing to meet those needs? According to LinkedIn's 2018 Workplace Learning Report, 94\% of employees would stay at a company if it invested in their career development. Yet, findings from Towards Maturity Benchmark Report 2018 show that only $1 \%$ of users are involved in the design of their learning."

So, employees are saying ongoing learning is paramount and yet they are not invited to the table. New generations of employees bring new expectations and cultural shifts in how they work and learn. Let's start by including them in the conversations.

\subsection{We embrace technology}

I have no doubt that one of the impacts of the current crisis will be an escalation in innovation in the tech sector with redirection of investment capital and expertise to 
enable the development of new tools to make digital content creation platforms accessible, responsive and engaging. Over the past decade we have seen this with web, blogging and podcast platforms. The challenge for Learning and Development professionals and designers is to re-engage with teachers and SMEs to facilitate a connection between the teacher and the learners where the individual teaching style is preserved and becomes the defining feature of online content design and to prevent teaching becoming pigeonholed by 'pro-forma' style online platforms. Individual style, personality and connection with students will need to be combined with the ability to produce online content quickly and effectively. The real-world examples I have given demonstrate how willing teachers are to embrace new ways to doing things as long as they are provided with the right tools and the right training.

\subsection{We find and nurture great educators}

To return to first principles, remember the key trait students looked for in a 'great teacher' were passion and confidence. These words encapsulate our role as L\&D professionals; to give teachers the confidence to continue to inspire and engage students with their passion for their chosen area of expertise.

The challenges brought about by the COVID-19 crisis are enormous, but I hope that we are able to embrace the opportunity to bring a new energy, sense of creativity and spirit of collaboration to our approach to learning and teaching.

\section{References}

[1] What is Online Learning? By Stephen Downes April, 062020 https://www.downes.ca/cgibin/page.cgi?post $=70701$

[2] LinkedIn 2018 Workplace Learning Report by Tanya Staples Feb 2018. https://learning.lin kedin.com/blog/learning-thought-leadership/introducing-the-2018-workplace-learningreport--talent-developme

[3] The Transformation Curve, Learning Benchmark Report Jan 2018. https://emeraldworks. com/research-and-reports/strategy/the-transformation-curve

[4] Profile of a modern learner by Kirstie Greaney Aug 15, 2018. https://www.elucidat.com/ blog/modern-learner-profile-infographic/

\section{$7 \quad$ Authors}

Natalie Wieland Founder of VidVersity, Teacher Melbourne University, Melbourne Law School, Executive Member of CLEAA (Continuing Legal Education Association Australia), AITD (Australian Institute of Training and Development), Council Member, Mentor RMIT VMX, Lawyer.

Liz Kollias Lawyer, Customer Relationship Manager, VidVersity.

Article submitted 2020-07-11. Resubmitted 2020-08-10. Final acceptance 2020-08-12. Final version published as submitted by the authors. 